\title{
Dural sinus malformation presenting with seizure and treated by combined arterial and venous embolization
}

Malformação dos seios durais apresentando-se com crises convulsivas e tratada com embolização arterial e venosa combinada

Ulysses C. Batista ${ }^{1,2}$, Thiago Giansante Abud ${ }^{1,2,3}$, Carlos Eduardo Baccin ${ }^{1,2,3}$, Renato Tavares Tosello ${ }^{1,2}$, Aron Athayde Diniz ${ }^{1,2}$, Benedito Jamilson Araújo Pereira ${ }^{1}$, Ronie Leo Piske $e^{1,2,3}$

A newborn with a prenatal diagnosis of dural sinus malformation, which was confirmed by an MRI (Figure 1). He was followed and at the first seizure (third month), a CT angiography was performed, which showed a partial thrombosis and an increase of the mass effects (Figure 2).

We performed three endovascular procedures (one per week) combining arterial and venous embolization, without complications (Figures 3 and 4). The patient was discharged without deficits.

A dural sinus malformation is a serious condition that can evolve into seizures and hemorrhage. It is characterized by a giant dural sinus lake associated with slow flow arteriovenous fistulae $e^{1,2,3}$.
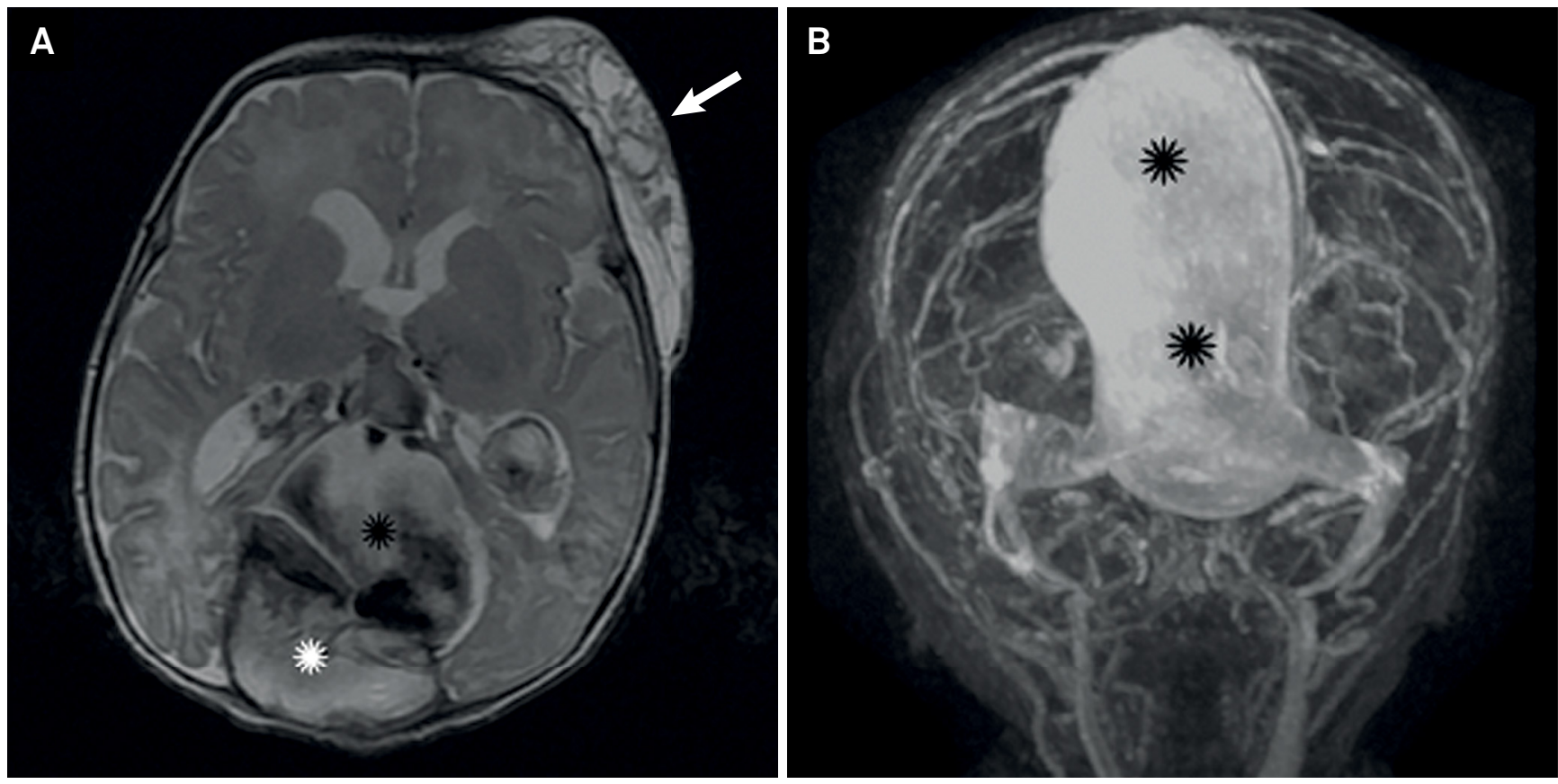

Figure 1. (A) Axial T2 weighted MRI of the brain showing the flow inside the dural venous malformation (black asterisk) and posteriorly of it, an area of partial thrombosis (white asterisk). A peripheral venous vascular malformation, commonly associated to the dural venous malformation, is indicated with the white arrow. (B) Coronal 3D MR angiogram after contrast injection showing the superior sagittal sinus malformation.

${ }^{1}$ Hospital Beneficência Portuguesa de São Paulo, Centro de Neuroangiografia (CNA), São Paulo SP, Brasil;

${ }^{2}$ Hospital Alvorada, Neuroradiologia Intervencionista, São Paulo SP, Brasil;

${ }^{3}$ Hospital Albert Einstein, Neuroradiologia Intervencionista, São Paulo SP, Brasil.

Correspondence: Ulysses C. Batista; Hospital Beneficência Portuguesa de São Paulo, Neuroradiologia Intervencionista; Rua Maestro Cardim, 769; 01323-900 São Paulo SP, Brasil; E-mail: ulyssescbatista@gmail.com

Conflict of interest: There is no conflict of interest to declare.

Received 19 October 2015; Receive in final form 29 August 2016; Accepted 31 March 2017. 

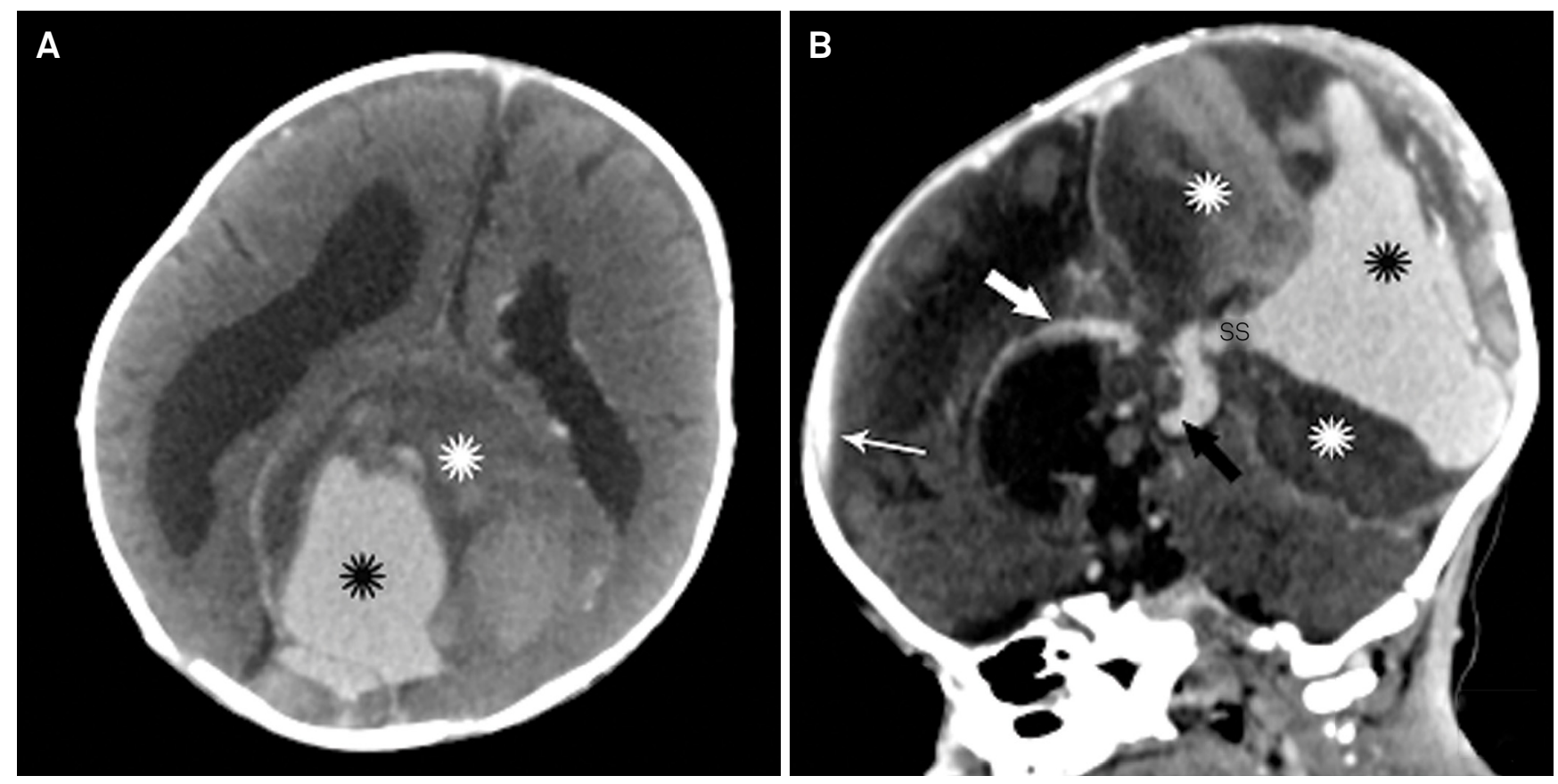

Figure 2. Axial (A) and sagittal (B) contrast enhanced CT angiography showing the extension of thrombosis (white asterisks) and the mass effect in the posterior sagittal sinus malformation (black asterisks). Note the communication between the straight sinus and the posterior superior sagittal sinus and the vein of Galen (black arrow). The anterior superior sagittal (white arrow) and inferior sagital sinus (large white arrow) are preserved.

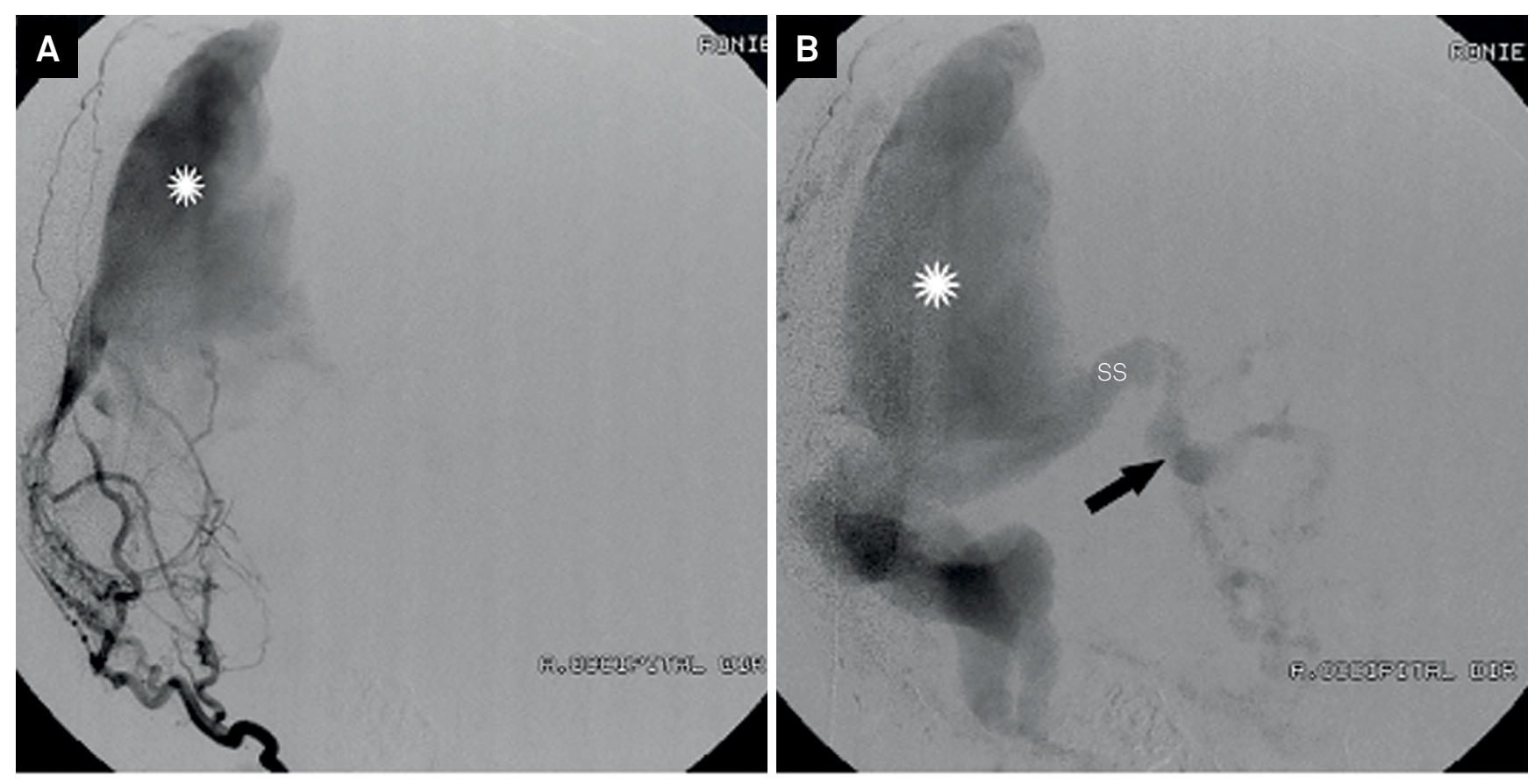

Figure 3. Lateral view of early (A) and late phase (B) occipital selective artery angiography showing a high flow dural arteriovenous fistula fed by meningeal branches from the occipital artery and feeding the superior sagittal sinus malformation (white asterisk). Note the dilated vein of Galen (black arrow) associated with deep venous hypertension and the superior sagittal sinus malformation (white asterisk). 


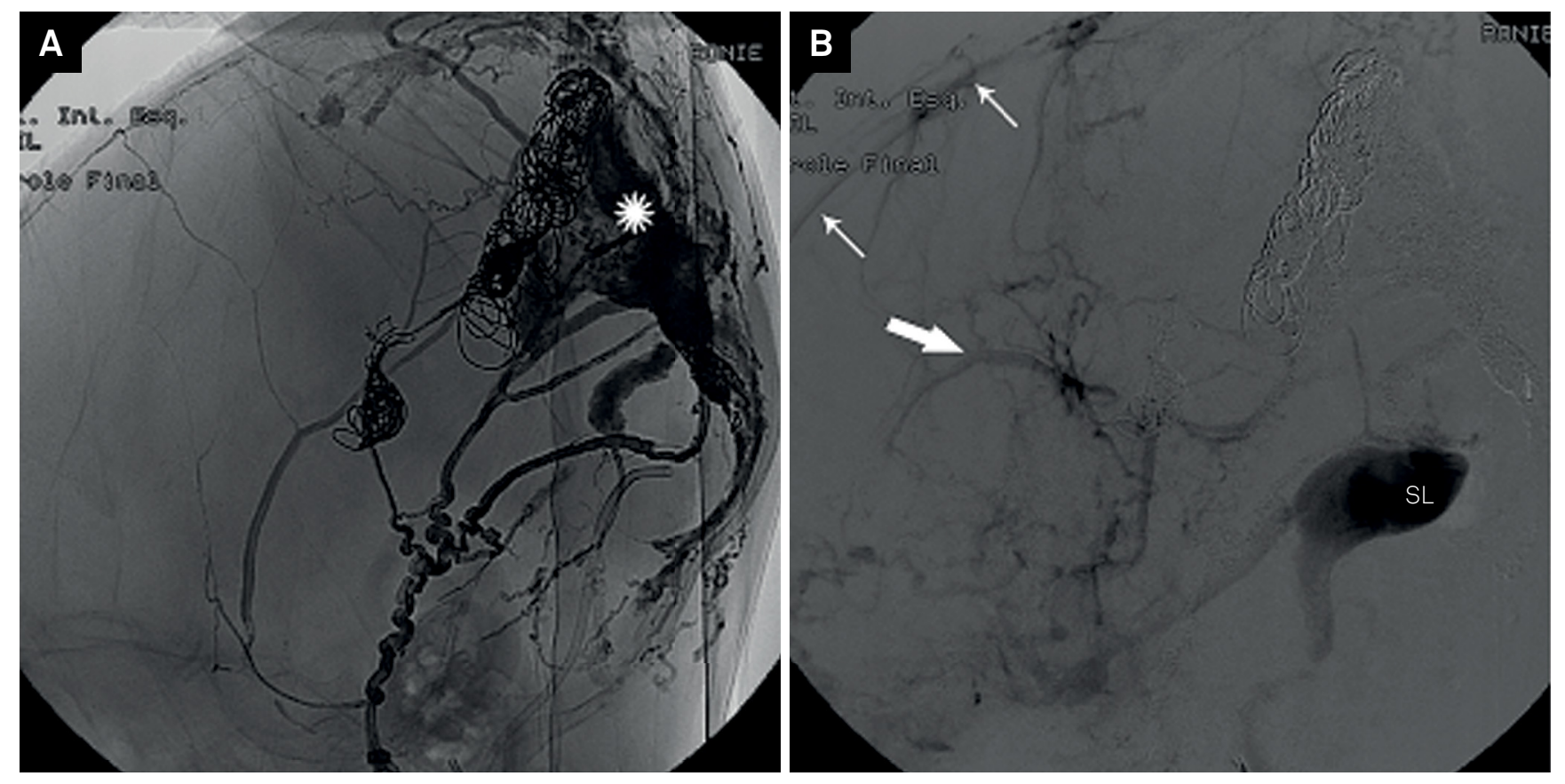

Figure 4. Lateral view final cast (A) of combining arterial and venous with liquid embolic and coil embolization filling the superior sagittal sinus malformation (white asterisk) and late phase of internal carotid digital angiography (B) after the endovascular embolization in the superior sagittal showing the lateral sinus (SL), the superior sagittal sinus (white arrows) and the internal cerebral vein (large white arrow) demonstrating that there was an improvement of the deep venous congestion.

\section{References}

1. Lasjaunias P, Magufis G, Goulao A, Piske R, Suthipongchai S, Rodesch R et al. Anatomical aspects of dural arteriovenous shunts in children. Intervent Neuroradiol. 1996;2(3):179-91.

2. Benoit Jenny, et al. Giant dural venous sinus ectasia in neonates Report of 4 cases. J Neurosurg Pediatrics. 2010;5(5):523-8.
3.

Rossi A, De Biasio P, Scarso E, Gandolfo C,

Pavanello M, Morana G et al. Prenatal MR imaging

of dural sinus malformation: a case report.

Prenat Diagn. 2006;26(1):11-6.

https://doi.org/10.1002/pd.1347 